\title{
Article \\ Mutation in OsFWL7 Affects Cadmium and Micronutrient Metal Accumulation in Rice
}

\author{
Qingsong Gao ${ }^{1,+}$, Lei Liu ${ }^{2,+}$, Haiying Zhou ${ }^{1}$, Xi Liu ${ }^{1}$, Wei Li ${ }^{1}$, Yu Min ${ }^{1}$, Yurong Yan ${ }^{1} \mathbb{D}$, Jianhui Ji ${ }^{1} \mathbb{D}$, \\ Hao Zhang ${ }^{2, *}$ and Xiangxiang Zhao ${ }^{1, *}$
}

1 Jiangsu Collaborative Innovation Center of Regional Modern Agriculture \& Environmental Protection/Jiangsu Key Laboratory for Eco-Agricultural Biotechnology around Hongze Lake, Huaiyin Normal University, Huai'an 223300, China; qsgao@hytc.edu.cn (Q.G.); hyzhou2018@163.com (H.Z.); 8201811078@hytc.edu.cn (X.L.); 18344870838@139.com (W.L.); m2567468323@163.com (Y.M.); y19852599546@163.com (Y.Y.); jijianhui@hytc.edu.cn (J.J.)

2 Jiangsu Key Laboratory of Crop Genetics and Physiology/Jiangsu Key Laboratory of Crop Cultivation and Physiology, Jiangsu Co-Innovation Center for Modern Production Technology of Grain Crops, Yangzhou University, Yangzhou 225009, China; liulei128478@163.com

* Correspondence: haozhang@yzu.edu.cn (H.Z.); xxz@hytc.edu.cn (X.Z.)

+ These authors have contributed equally to this work.

check for updates

Citation: Gao, Q.; Liu, L.; Zhou, H.; Liu, X.; Li, W.; Min, Y.; Yan, Y.; Ji, J.; Zhang, H.; Zhao, X. Mutation in OsFWL7 Affects Cadmium and Micronutrient Metal Accumulation in Rice. Int. J. Mol. Sci. 2021, 22, 12583. https://doi.org/10.3390/ijms 222212583

Academic Editor:

Pedro Martínez-Gómez

Received: 15 September 2021

Accepted: 19 November 2021

Published: 22 November 2021

Publisher's Note: MDPI stays neutral with regard to jurisdictional claims in published maps and institutional affiliations.

Copyright: (c) 2021 by the authors. Licensee MDPI, Basel, Switzerland. This article is an open access article distributed under the terms and conditions of the Creative Commons Attribution (CC BY) license (https:/ / creativecommons.org/licenses/by/ $4.0 /)$.

\begin{abstract}
Micronutrient metals, such as $\mathrm{Mn}, \mathrm{Cu}, \mathrm{Fe}$, and $\mathrm{Zn}$, are essential heavy metals for plant growth and development, while $\mathrm{Cd}$ is a nonessential heavy metal that is highly toxic to both plants and humans. Our understanding of the molecular mechanisms underlying $\mathrm{Cd}$ and micronutrient metal accumulation in plants remains incomplete. Here, we show that OsFWL7, an FW2.2-like (FWL) family gene in Oryza sativa, is preferentially expressed in the root and encodes a protein localized to the cell membrane. The osfwl7 mutation reduces both the uptake and the root-to-shoot translocation of $\mathrm{Cd}$ in rice plants. Additionally, the accumulation of micronutrient metals, including $\mathrm{Mn}, \mathrm{Cu}$, and $\mathrm{Fe}$, was lower in osfwl7 mutants than in the wildtype plants under normal growth conditions. Moreover, the osfwl7 mutation affects the expression of several heavy metal transporter genes. Protein interaction analyses reveal that rice FWL proteins interact with themselves and one another, and with several membrane microdomain marker proteins. Our results suggest that OsFWL7 is involved in $\mathrm{Cd}$ and micronutrient metal accumulation in rice. Additionally, rice FWL proteins may form oligomers and some of them may be located in membrane microdomains.
\end{abstract}

Keywords: rice; FW2.2-like gene; cadmium; micronutrient metal; protein interaction; membrane microdomain

\section{Introduction}

Micronutrient metals, such as $\mathrm{Mn}, \mathrm{Cu}, \mathrm{Fe}$, and $\mathrm{Zn}$, are essential heavy metals for plant growth and development [1]. In contrast, $\mathrm{Cd}$ is a nonessential heavy metal that is highly toxic. It disrupts plant growth and development, thereby substantially reducing crop yield. Moreover, upon entering the food chain, it threatens public health $[2,3]$. Therefore, elucidating the molecular mechanisms underlying plant $\mathrm{Cd}$ and micronutrient metal accumulation will aid the development of crop varieties with enhanced nutrient uptake and reduced $\mathrm{Cd}$ accumulation.

Rice (Oryza sativa L.) is one of the most important cereal crops worldwide. Since Cd is nonessential for growth, plants may not possess a specific transporter for this metal, and $\mathrm{Cd}$ likely enters rice cells via transporters for essential metals. OsNramp5 is mainly expressed in rice roots and encodes a plasma membrane-localized transporter [4,5]. The loss-of-function mutation of this gene results in an extremely low $\mathrm{Cd}$ accumulation in roots, shoots, and grains, suggesting that OsNramp5 is a major transporter for Cd uptake in rice $[4,6]$. However, OsNramp5 also acts as a Mn transporter, and the knockout of this gene significantly reduces plant growth [4]. Cd taken up from soil is sequestered into 
the vacuoles of root cells, and OsHMA3-a $\mathrm{P}_{1 \mathrm{~B}}$-type ATPase-plays an important role in this process $[7,8]$. This transporter is localized to the tonoplast of all root cells, and the expression of gene encoding OsHMA3 is unaffected by $\mathrm{Cd}$ treatment. The loss of protein function decreases the vacuolar sequestration of $\mathrm{Cd}$ in roots, resulting in high root-to-shoot translocation [7-10]. However, the overexpression of this gene also increases the $\mathrm{Zn}$ content of roots, suggesting that OsHMA3 may originally be a $\mathrm{Zn}$ transporter [11]. The root-to-shoot transportation of Cd is mediated by OsHMA2, a homolog of OsHMA3 [12-14]. OsHMA2 is also a $\mathrm{Zn}$ transporter [12]. Additionally, the plasma membrane-localized transporters OsIRT1 and OsIRT2 are involved in Fe uptake [15]. $\mathrm{Cu}$ is mainly taken up by COPT transporters, such as COPT1 and COPT5, and loaded into the xylem for transportation by OsHMA5 [16-18]. Unfortunately, despite great research progress, our understanding of the molecular mechanisms underlying $\mathrm{Cd}$ and micronutrient metal accumulation in rice remains incomplete.

FW2.2 is the key regulator of tomato fruit size and weight, and a negative regulator of cell proliferation during fruit development $[19,20]$. The FW2.2 protein harbors an uncharacterized placenta-specific 8 domain, and is localized to the plasma membrane [21,22]. $F W 2.2-$ like $(F W L)$ genes have been characterized in various plant species and reported to perform diverse functions [23-25]. Cell Number Regulator1 (CNR1), an FWL gene in maize, negatively regulates plant and organ size by controlling cell division [22]. Similarly, Physalis floridana CNR1 negatively affects the size of multiple organs by altering the cell number [26]. Additionally, the soybean FWL gene GmFWL1 plays a pivotal role in nodulation [27]. RNA interference-mediated knockdown of GmFWL1 significantly reduced the nodule number. Interestingly, GmFWL1 is a plasma membrane microdomain-associated protein [28]. In addition, FWL proteins play important roles in heavy metal homeostasis. FWL homologs in Arabidopsis have been named Plant Cadmium Resistance genes (PCRs). In particular, AtPCR1 overexpression enhances $\mathrm{Cd}$ tolerance in both yeast and Arabidopsis by reducing its accumulation [29]. AtPCR2 forms homo-oligomers in the plasma membrane and mediates $\mathrm{Zn}$ transport in Arabidopsis [30]. Additionally, overexpression of the common wheat FWL gene TaCNR2 and the diploid wheat FWL gene TuCNR10 in Arabidopsis and rice improved the tolerance and translocation of $\mathrm{Cd}, \mathrm{Zn}$, and $\mathrm{Mn}[31,32]$.

Previously, eight $F W L$ genes (OsFWL1-OsFWL8) were identified in the rice genome [33]. Among these, OsCNR1/FWL1 determines rice grain width and weight by influencing cell division and expansion in the glumes [34]. Changes in OsFWL1 and OsFWL2 expression affect $\mathrm{Cd}$ tolerance and accumulation [35]. OsFWL4 can form homo-oligomers in the plasma membrane and is involved in the root-to-shoot transportation of Cd [36]. Additionally, this protein acts as a negative regulator of rice tiller number [37]. OsPCR1/FWL5 is localized to the plasma membrane as an oligomer and affects the grain weight and Zn content [38].

In this study, we aimed to characterize the role of OsFWL7 (LOC_Os03g61500) in heavy metal accumulation. Cd treatment induced significant OsFWL7 expression in roots. Moreover, the osfwl7 mutation reduced the accumulation of $\mathrm{Cd}$ and micronutrient metals, including $\mathrm{Mn}, \mathrm{Cu}$, and $\mathrm{Fe}$, in rice. We also found that the rice FWL proteins self-interact and interact with one another, and that some of them may be located in membrane microdomains.

\section{Results}

\subsection{Characterization of OsFWL7}

Previous studies have reported that the expression of several rice FWL genes may enhance the Cd tolerance of sensitive yeast cells $[29,36]$. To test whether the FWL genes are involved in Cd response in rice, the expression patterns of six genes (OsFWL1-OsFWL4, OsFWL6, and OsFWL7) under Cd exposure at different concentrations were examined using reverse-transcription quantitative PCR (RT-qPCR). Actin1, a commonly used reference gene in rice [39,40], was used for data normalization. The expression of only two genes, namely OsFWL4 and OsFWL7, was found to be significantly altered (Figure 1A). The OsFWL4 transcript level increased in roots but decreased in shoots following exposure to $100 \mu \mathrm{M} \mathrm{Cd}$, 
which is consistent with previous reports [36]. Cd exposure markedly induced OsFWL7 expression in the roots (Figure 1A). However, the OsFWL7 transcript level was below the limit of detection in shoots both under normal conditions and all Cd treatments. Next, we examined the expression profile of this gene in different tissues and observed that OsFWL7 was predominantly expressed in the roots (Figure 1B). The expression patterns of OsFWL7 in different tissues and under $\mathrm{Cd}$ treatments were also analyzed using rice ubiquitin gene (LOC_Os03g13170) as a reference [41], and similar results were obtained (Figure S1).
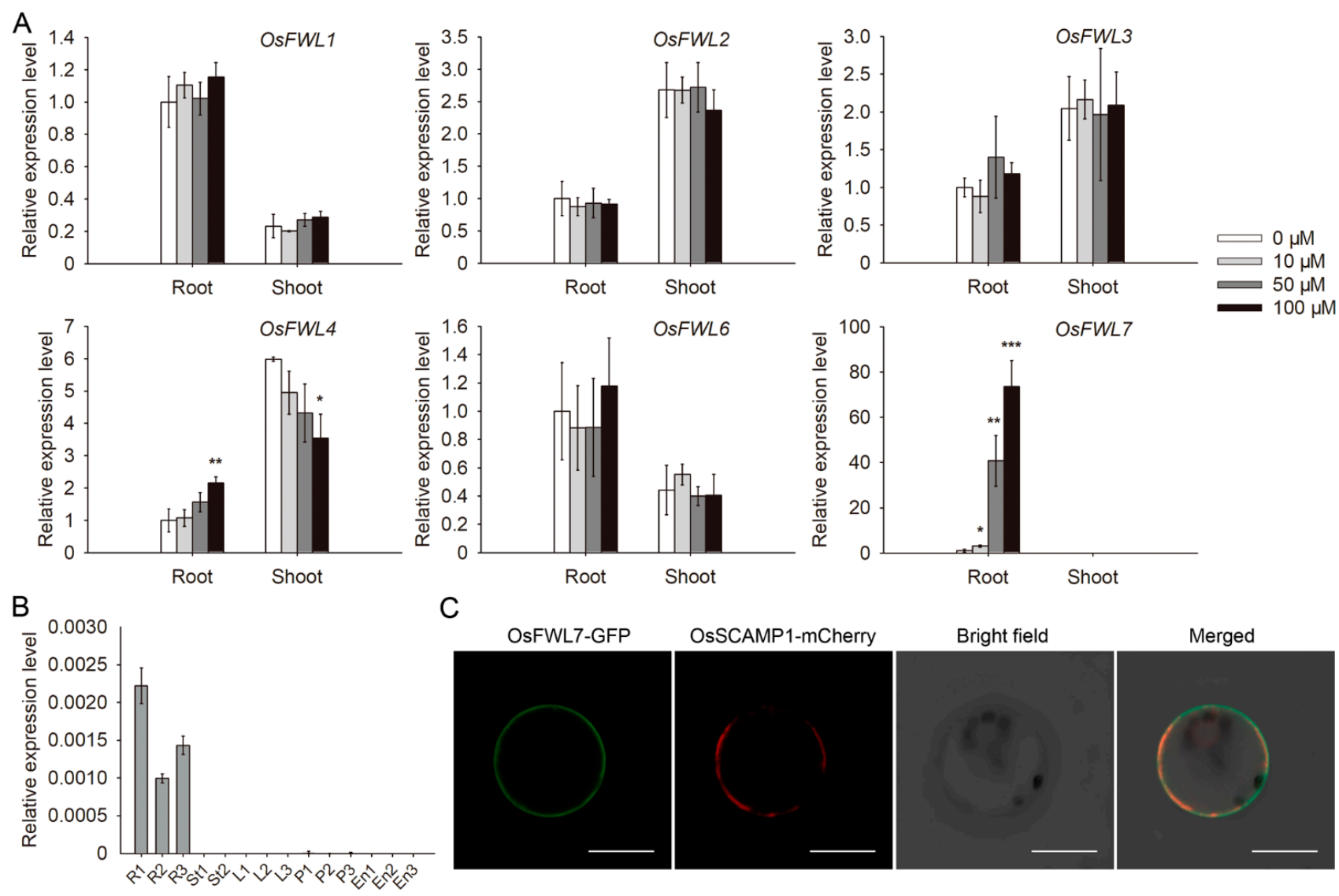

Figure 1. Gene expression profiles and subcellular localization of OsFWL7. (A) Expression patterns of six rice FWL genes under treatment with $\mathrm{Cd}$ of different concentrations, as determined using RT-qPCR. The rice Actin1 gene was used for normalization of gene expression. Error bars indicate the standard deviation of three biological replicates. ${ }^{*} p<0.05$, ${ }^{* *} p<0.01,{ }^{* * *} p<0.001$. (B) OsFWL7 expression patterns in 14 tissue samples of Oryza sativa L. ssp. japonica variety Zhonghua 11, as determined using RT-qPCR. The tissues used were as follows: seedling, tillering, and heading stage roots (R1-R3); jointing and heading stage stems (St1 and St2); seedling, tillering, and heading stage leaves (L1-L3); 5-, 15-, and 20-cm panicles (P1-P3); and endosperms 5, 14, and 21 days after pollination (En1-En3). Error bars indicate the standard deviation of three technical replicates. (C) Subcellular localization of OsFWL7. The OsSCAMP1-mCherry construct was used as the plasma membrane marker. The GFP fluorescence, mCherry fluorescence, bright field, and merged images are shown. Bar $=10 \mu \mathrm{m}$.

Protein sequence analysis using TMHMM Server v. 2.0 (https:/ / services.healthtech. dtu.dk/service.php?TMHMM-2.0) predicted a transmembrane helix in the 50-72 region of OsFWL7 (Figure S2). The protein was fused with GFP to determine its subcellular localization. A known plasma membrane protein, OsSCAMP1 [42], was fused with mCherry and used as the marker. GFP fluorescence was detected only in the plasma membrane of rice protoplasts and co-localized with mCherry fluorescence (Figure 1C), suggesting that OsFWL7 is localized to the cell membrane. 


\section{2. osfwl7 Mutants Are Less Sensitive to $C d$}

We have previously designed two target sites (Osfwl7a and Osfwl7b) in the OsFWL7 gene for clustered regularly interspaced short palindromic repeats (CRISPR)/CRISPRassociated protein 9 (Cas9)-mediated genome editing [37]. Both the target sites were located in the second exon of the gene (Figure S3A). For Osfwl7a target, $13 \mathrm{~T} 0$ mutants were obtained, among which two were homozygotes [37]. For Osfwl7b target, $12 \mathrm{~T} 0$ mutants were obtained and five of them were homozygotes. We selected one homozygous mutant of each target for further analysis, and designated them osfwl7 $a$ and $o s f w l 7 b$, respectively. Both mutant lines harbored a 1 bp insertion in the coding region (Figure S3B,C), which caused frame-shift mutations in the gene. The grain yield per plant and plant height of osfwl7 mutants grown under normal field conditions were not significantly different from those of the wildtype (WT) (Figure S4).

To investigate the biological function of OsFWL7 in Cd response, the osfwl7a and osfwl $7 b$ mutants were treated with $50 \mu \mathrm{M} \mathrm{Cd}$. Under normal growth conditions, the shoot length of osfwl7 mutants was similar to that of the WT, but the root length was slightly lower (Figure 2A-C). Cd markedly inhibited shoot and root elongation in both WT and mutant plants (Figure 2A-C). However, the shoots and roots of osfwl7 mutants were significantly longer than those of the WT under Cd stress (Figure 2A-C). The shoot dry weight of osfwl7 mutants was greater than that of the WT, both under normal conditions and Cd stress (Figure 2D). The root dry weight of osfwl7 mutants did not evidently differ from that of the WT under normal conditions, but was markedly greater under Cd stress (Figure 2E). Among leaf pigments, the chlorophyll and carotenoid contents of both WT and mutant plants decreased following $\mathrm{Cd}$ treatment. However, this decrease was significantly smaller in osfwl7 mutants (Figure 2F,G). Taken together, these results suggest that osfwl7 mutants are less sensitive to $\mathrm{Cd}$ stress.

\subsection{OsFWL7 Is Involved in Cd Uptake and Translocation}

To test whether the osfwl7 mutation affects $\mathrm{Cd}$ accumulation, $\mathrm{Cd}$ concentrations in the roots and shoots of WT and mutant plants under $\mathrm{Cd}$ treatment were determined. The $\mathrm{Cd}$ concentrations in both roots and shoots were significantly lower in the osfwl7 mutants than in the WT (Figure 3A). Additionally, the proportion of Cd distributed to the shoots was lower in osfwl7 mutants (Figure 3B). These results suggest that OsFWL7 is involved in both $\mathrm{Cd}$ uptake and translocation.

\section{4. osfwl7 Mutation Affects Micronutrient Metal Accumulation in Rice}

To test whether the osfwl7 mutation affects the accumulation of micronutrient metals in rice, $\mathrm{Mn}, \mathrm{Cu}, \mathrm{Fe}$, and $\mathrm{Zn}$ levels in seedlings with and without $\mathrm{Cd}$ treatment were determined. In the absence of $\mathrm{Cd}, \mathrm{Mn}$ levels in both roots and shoots of osfwl7 mutants were significantly lower than in those of the WT (Figure 4A,E). Similarly, Cu levels in the roots of osfwl7 mutants were significantly lower than those of the WT under normal conditions (Figure 4B); however, $\mathrm{Cu}$ levels in the shoots of WT and mutants were comparable (Figure 4F). Fe levels in the roots of WT and osfwl7 mutants grown under normal conditions did not differ (Figure 4C), but its levels in the shoots were significantly lower in the mutants (Figure 4G). Additionally, $\mathrm{Zn}$ levels in the roots of osfwl7a and in the shoots of both mutants were comparable to those of the WT under normal conditions (Figure 4D,H); however, Zn levels were increased in the roots of osfwl7b (Figure 4D).

In the presence of $\mathrm{Cd}, \mathrm{Cu}$ and Fe levels in the roots of osfwl7 mutants were lower and higher, respectively, than in those of the WT (Figure 4B,C). Mn levels in the roots were slightly lower in osfwl $7 b$ but higher in osfwl7 a under Cd stress (Figure 4A). No significant difference was noted in Zn levels in the roots of the WT and the osfwl7 mutants under $\mathrm{Cd}$ stress (Figure 4D). Additionally, no marked difference was noted in $\mathrm{Mn}, \mathrm{Cu}, \mathrm{Fe}$, and $\mathrm{Zn}$ levels in the shoots under $\mathrm{Cd}$ treatment (Figure $4 \mathrm{E}-\mathrm{H}$ ). Collectively, these results suggest that the osfwl7 mutation affects micronutrient metal accumulation in rice. 
A
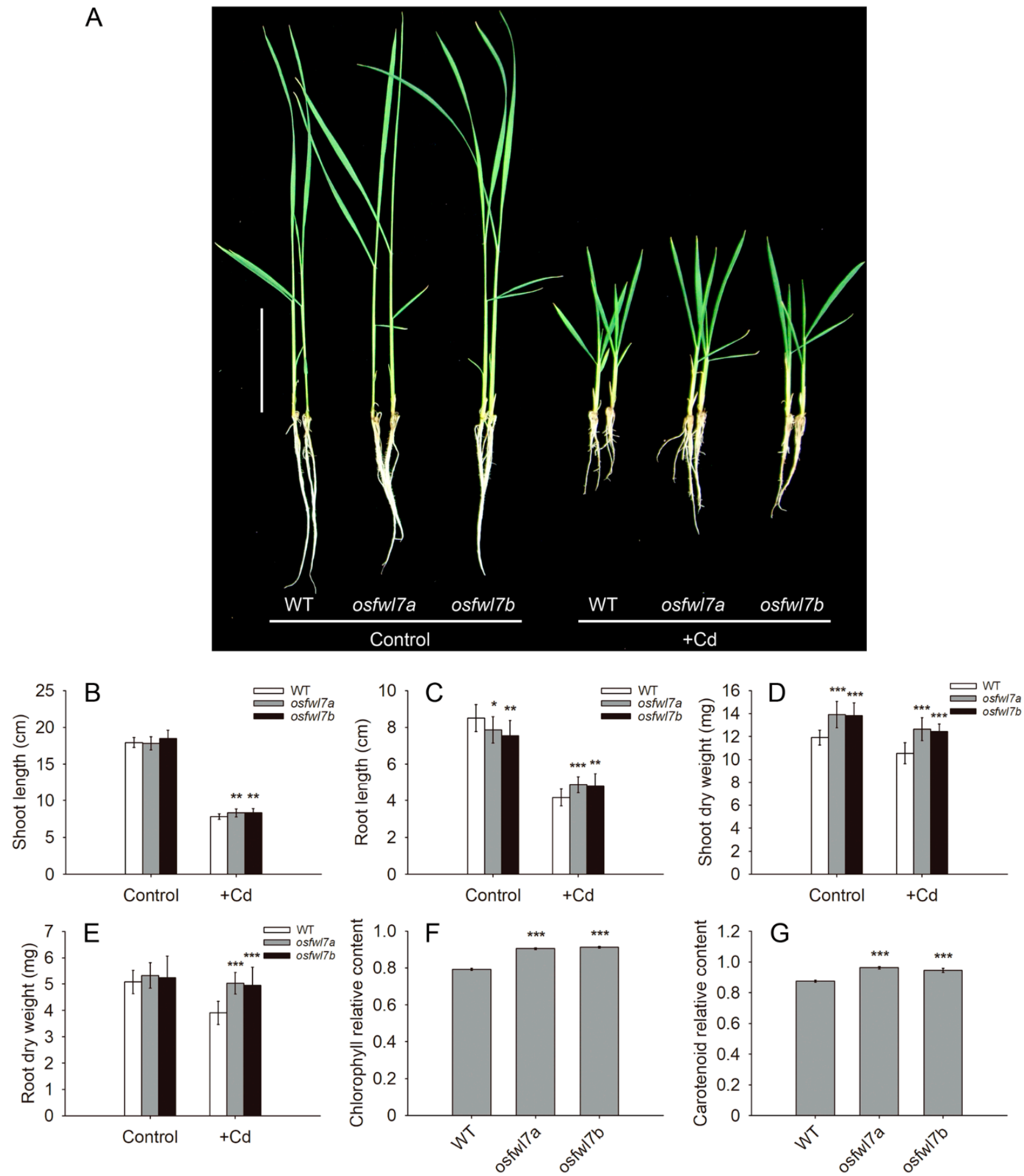

Figure 2. Performance of the wildtype (WT) and osfwl7 mutants under Cd stress. (A) WT and mutant plants grown under normal conditions and in the presence of $50 \mu \mathrm{M} \mathrm{Cd}$ for 10 days, bar $=5 \mathrm{~cm}$. (B-E) Shoot length (B), root length (C), shoot dry weight (D), and root dry weight (E) of the WT and mutants, $n=15$. Error bars indicate standard deviation. (F) Relative chlorophyll content of the WT and mutants (chlorophyll content under Cd stress/chlorophyll content under normal condition). (G) Relative carotenoid content of the WT and mutants (carotenoid content under Cd stress/carotenoid content under normal condition). Error bars in $(\mathbf{F}, \mathbf{G})$ indicate the standard deviation of three biological replicates. ${ }^{*} p<0.05$, ${ }^{* *} p<0.01,{ }^{* * *} p<0.001$. 

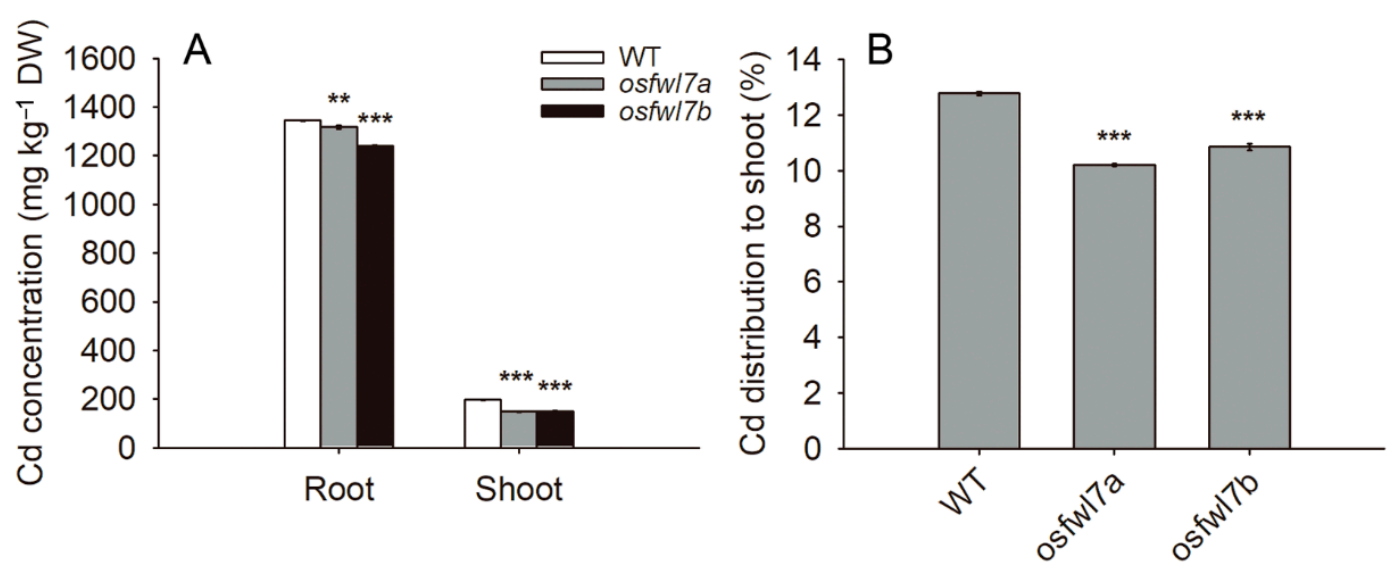

Figure 3. Effect of osfwl7 mutation on Cd accumulation and translocation. (A) Measurement of Cd levels in the wildtype (WT) and osfwl7 mutants grown in the presence of $50 \mu \mathrm{M} \mathrm{Cd}$ for 10 days. (B) The percentage of Cd distributed to the shoot. Error bars indicate the standard deviation of three biological replicates. ${ }^{* *} p<0.01,{ }^{* * *} p<0.001$.

\section{5. osfwl7 Mutation Affects the Expression of Heavy Metal Transporter Genes}

To elucidate the mechanisms underlying changes in heavy metal concentrations in osfwl7 mutants, the expression levels of several heavy metal transporter genes in seedling roots of the WT and the mutants were compared. OsNramp5 is the major transporter for $\mathrm{Mn}$ and Cd uptake in rice [4-6]. The transcript levels of OsNramp 5 were significantly lower in osfwl7 mutants both under normal and Cd stress conditions (Figure 5). Moreover, OsNramp6 functions as the transporter for Fe and Mn [43]. The transcript levels of OsNramp6 were lower in the osfwl7 mutants than in the WT under normal conditions, but comparable under $\mathrm{Cd}$ stress (Figure 5). OsCOPT5 is the transporter associated with Cu uptake and redistribution [17], while OsHMA5 is involved in Cu xylem loading [18]. The transcript levels of OsHMA5 and OsCOPT5 were significantly lower in osfwl7 mutants than in the WT under Cd stress (Figure 5). OsHMA2 is involved in the root-to-shoot translocation of $\mathrm{Zn}$ and Cd [12-14]. The transcript level of OsHMA2 was significantly lower in the osfwl7a mutant than in the WT under Cd stress. Additionally, OsNramp3 functions as a switch for Mn distribution [44]. However, the transcript levels of OsNramp3 did not significantly differ between the WT and the osfwl7 mutants both under normal and Cd stress conditions (Figure 5). Together, these results suggest that osfwl7 mutation affects the expression of several heavy metal transporter genes.

\subsection{Rice FWL Proteins Interact with Themselves and One Another}

In addition to OsFWL7, discussed in this study, six other rice FWL proteins, namely OsFWL1-OsFWL6, have been found to be plasma membrane proteins [33,38]. The plasma membrane-bound plant FWL proteins, such as AtPCR2, OsFWL4, and OsPCR1/FWL5, form homo-oligomers $[30,36,38]$. To test whether other plasma membrane-bound rice FWL proteins can self-interact, we performed yeast two-hybrid assays and found that all plasma membrane-bound rice FWL proteins interacted with themselves in yeast cells (Figure 6A). Bimolecular fluorescence complementation (BiFC) assays confirmed the self-interaction of OsFWL7 in the cell membrane (Figure 6B).

We next examined whether the plasma membrane-bound rice FWL proteins can interact with one another using yeast two-hybrid assays and found that all proteins interacted with one another in the yeast cells (Figure 6A). Together, these results indicate that the rice FWL proteins interact with themselves and one another. 

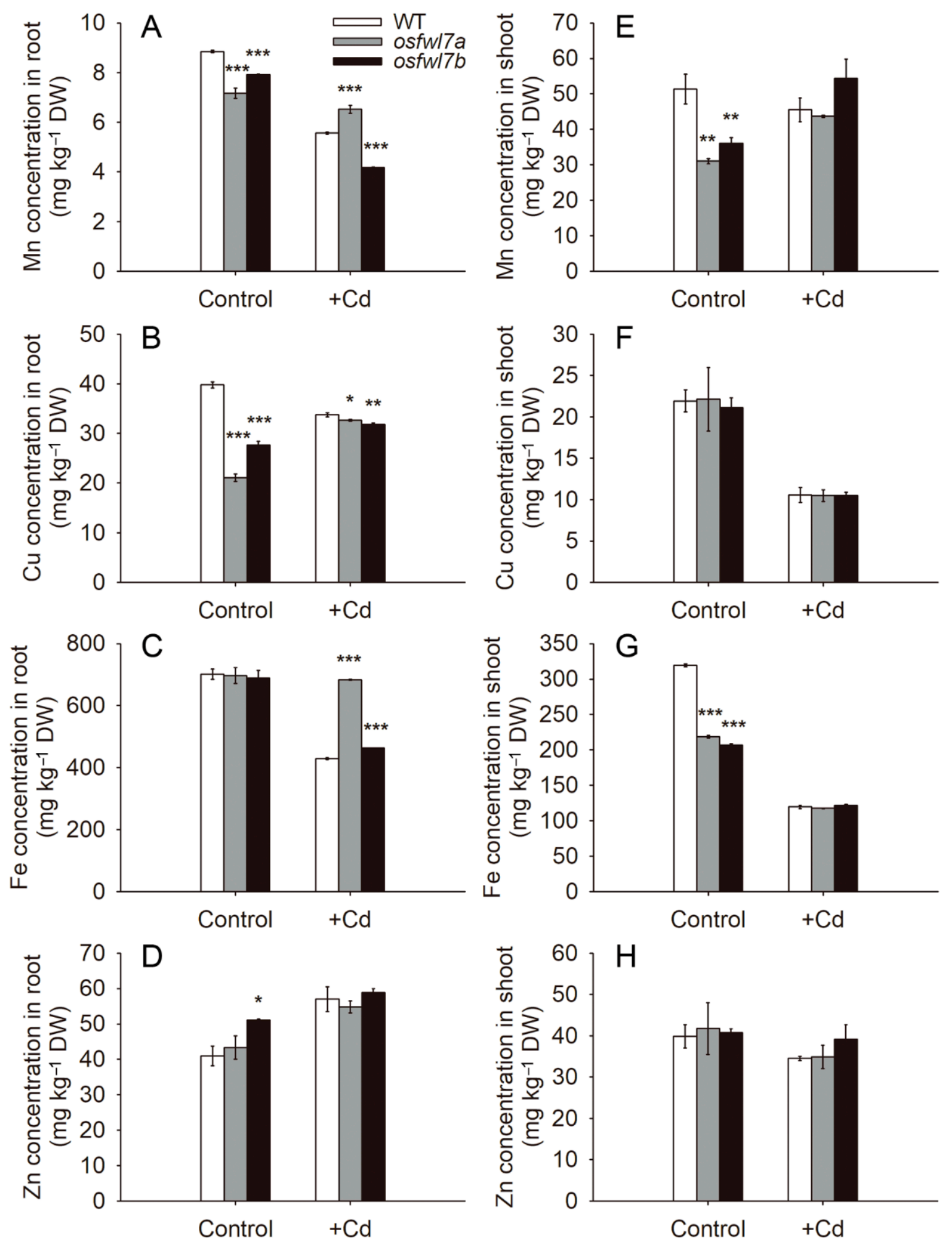

Figure 4. Effect of the osfwl7 mutation on micronutrient metal accumulation. (A-D) Measurement of $\mathrm{Mn}(\mathbf{A}), \mathrm{Cu}(\mathbf{B}), \mathrm{Fe}(\mathrm{C})$, and $\mathrm{Zn}(\mathrm{D})$ levels in roots of the wildtype (WT) and mutants grown under normal conditions and in the presence of $50 \mu \mathrm{M}$ $\mathrm{Cd}$ for 10 days. (E-H) Measurement of $\mathrm{Mn}(\mathbf{E}), \mathrm{Cu}(\mathbf{F}), \mathrm{Fe}(\mathrm{G})$, and $\mathrm{Zn}(\mathbf{H})$ levels in the shoots of WT and mutants. Error bars indicate the standard deviation of three biological replicates. ${ }^{*} p<0.05,{ }^{* *} p<0.01,{ }^{* * *} p<0.001$. 

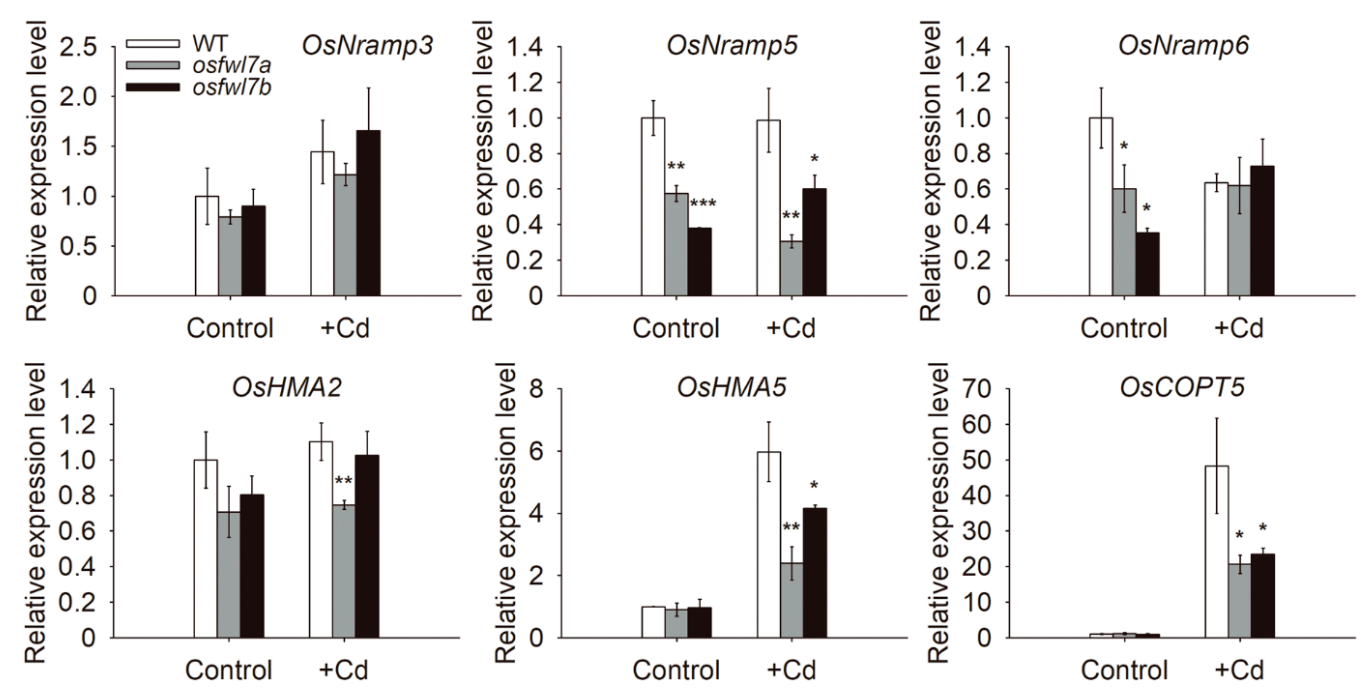

Figure 5. Expression patterns of heavy metal transporter genes in the wildtype (WT) and osfwl7 mutants determined using RT-qPCR. The genes assayed were as follows: OsNramp3 (LOC_Os06g46310), OsNramp5 (LOC_Os07g15370), OsNramp6 (LOC_Os01g31870), OsHMA2 (AB697186), OsHMA5 (LOC_Os04g46940), and OsCOPT5 (LOC_Os05g35050). The rice Actin1 gene was used for normalization of gene expression. Error bars indicate the standard deviation of three biological replicates. ${ }^{*} p<0.05,{ }^{* *} p<0.01,{ }^{* * *} p<0.001$.

\subsection{Rice FWL Proteins Interact with Membrane Microdomain Marker Proteins}

The GmFWL1 protein is located in the plasma membrane microdomains $[27,28]$, and remorins and prohibitins are considered the marker proteins of membrane microdomains $[45,46]$. To test whether the rice FWL proteins are membrane microdomain-associated proteins, the interactions of the seven plasma membrane-bound rice FWL proteins with two remorin family proteins (LP1 and GSD1) [47,48] and two prohibitin family proteins (LOC_Os04g38900 and LOC_Os03g62490) were examined using yeast two-hybrid assays. All tested rice FWL proteins, except OsFWL2, interacted with LOC_Os03g62490 in yeast cells (Figure 7A). Five proteins (OsFWL1, OsFWL3, OsFWL5-OsFWL7) interact with LOC_Os04g38900. However, only OsFWL1, OsFWL3, and OsFWL6 interacted with LP1, and OsFWL3 interacted with GSD1 (Figure 7A). The interactions between OsFWL7 and the two prohibitin family proteins were further verified by BiFC (Figure 7B,C). Collectively, these results indicate that rice FWL proteins interact with membrane microdomain marker proteins.
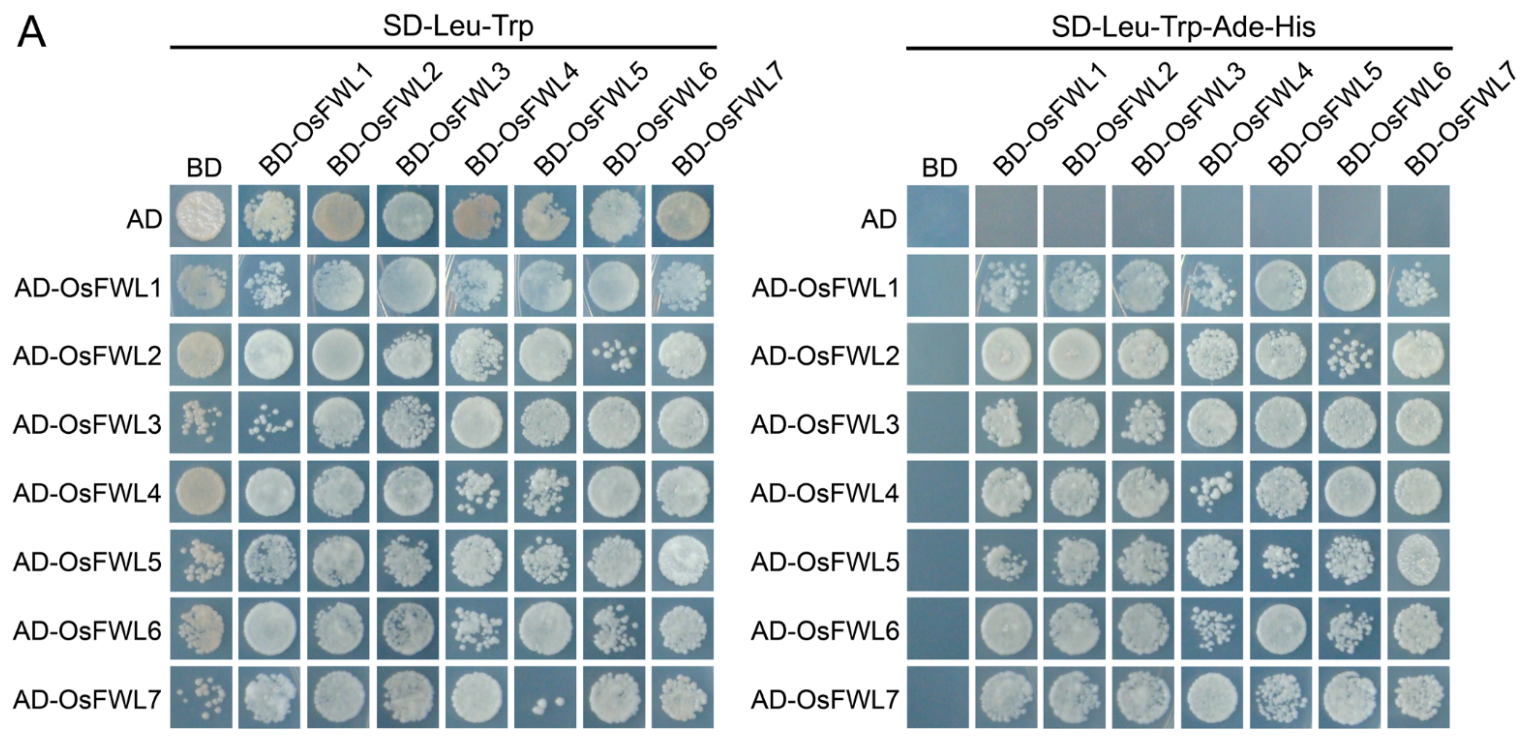

Figure 6. Cont. 
B

OSFWL7-nYFP+ OsFWL7-cYFP
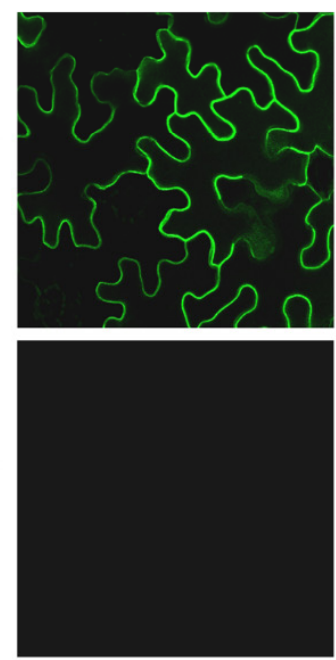

OsSCAMP1-mCherry
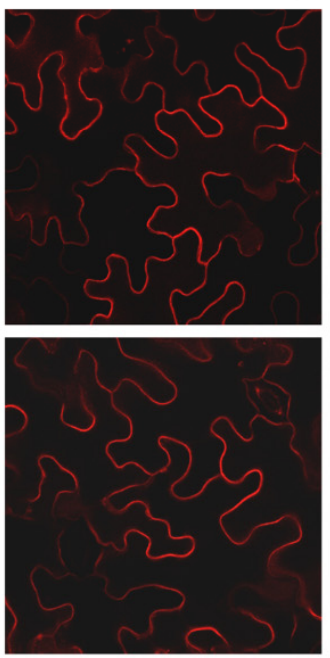

Bright field
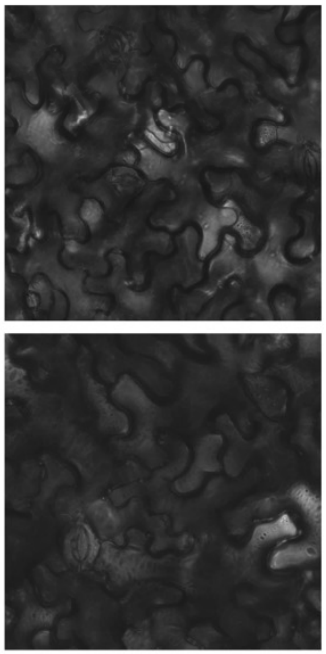

Merged
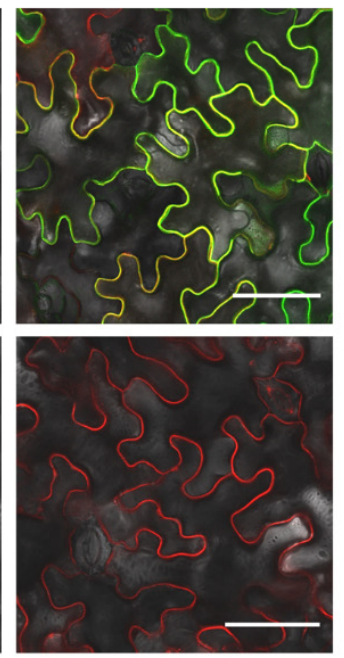

Figure 6. Detection of the interactions of rice FWL proteins. (A) Yeast two-hybrid assays showing that all tested rice FWL proteins interact with themselves and one another. Transformed yeast cells were cultured on SD-Leu-Trp control medium and SD-Leu-Trp-Ade-His selective medium. Yeast strains containing the OsFWL-BD and empty pGADT7 vectors, the OsFWL-AD and empty pGBKT7 vectors, or the empty pGADT7 and pGBKT7 vectors were used as negative controls. AD, activation domain; BD, DNA binding domain. (B) Bimolecular fluorescence complementation (BiFC) assays showing self-interaction of OsFWL7 in leaf epidermal cells of Nicotiana benthamiana. The OsSCAMP1 protein was fused with mCherry and used as the plasma membrane marker. The YFP fluorescence, mCherry fluorescence, bright field, and merged images are shown. Bar $=50 \mu \mathrm{m}$.

A

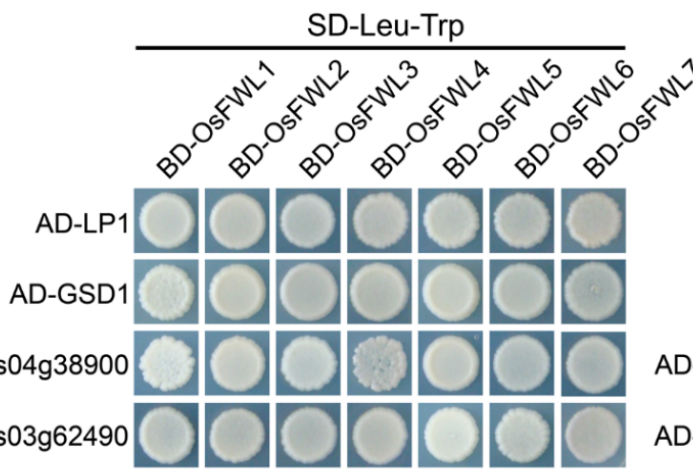

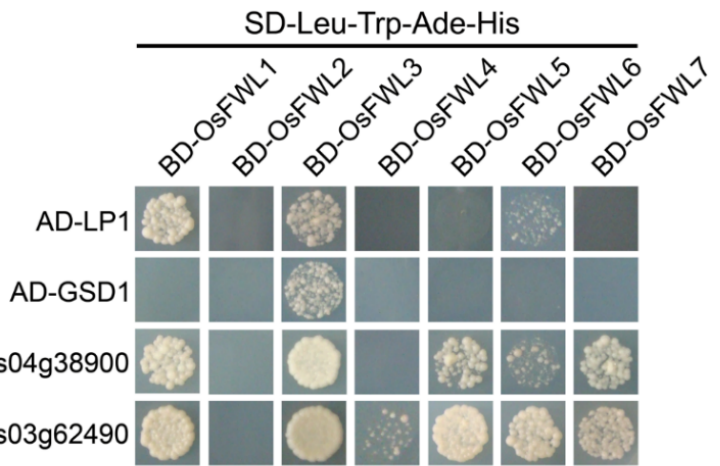

B

OsFWL7-nYFP+ Os04g38900-cYFP
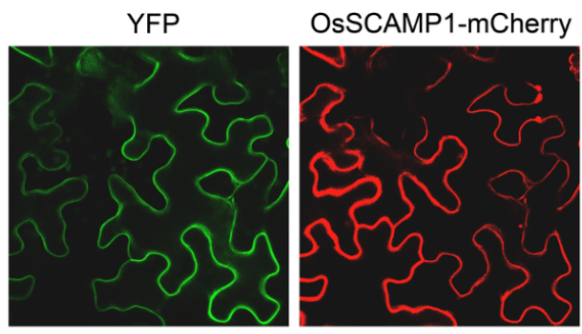

nYFP+

Os04g38900-cYFP
Bright field
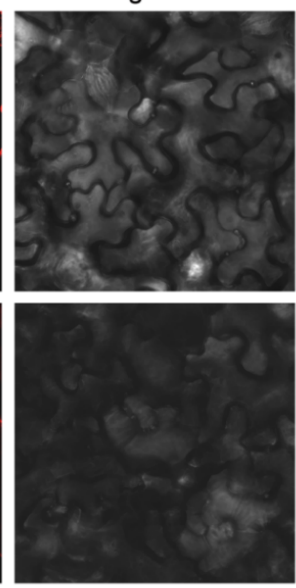

Merged
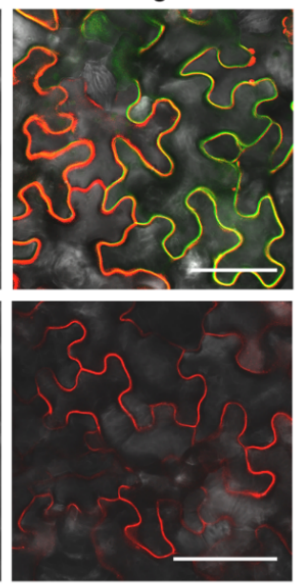
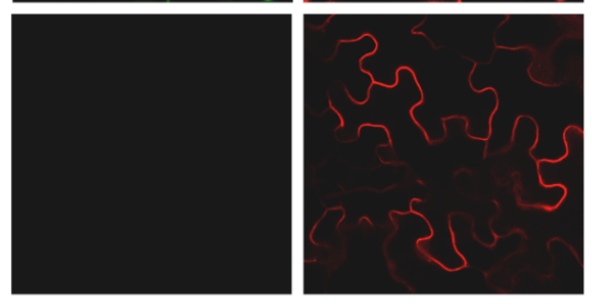

Figure 7. Cont. 

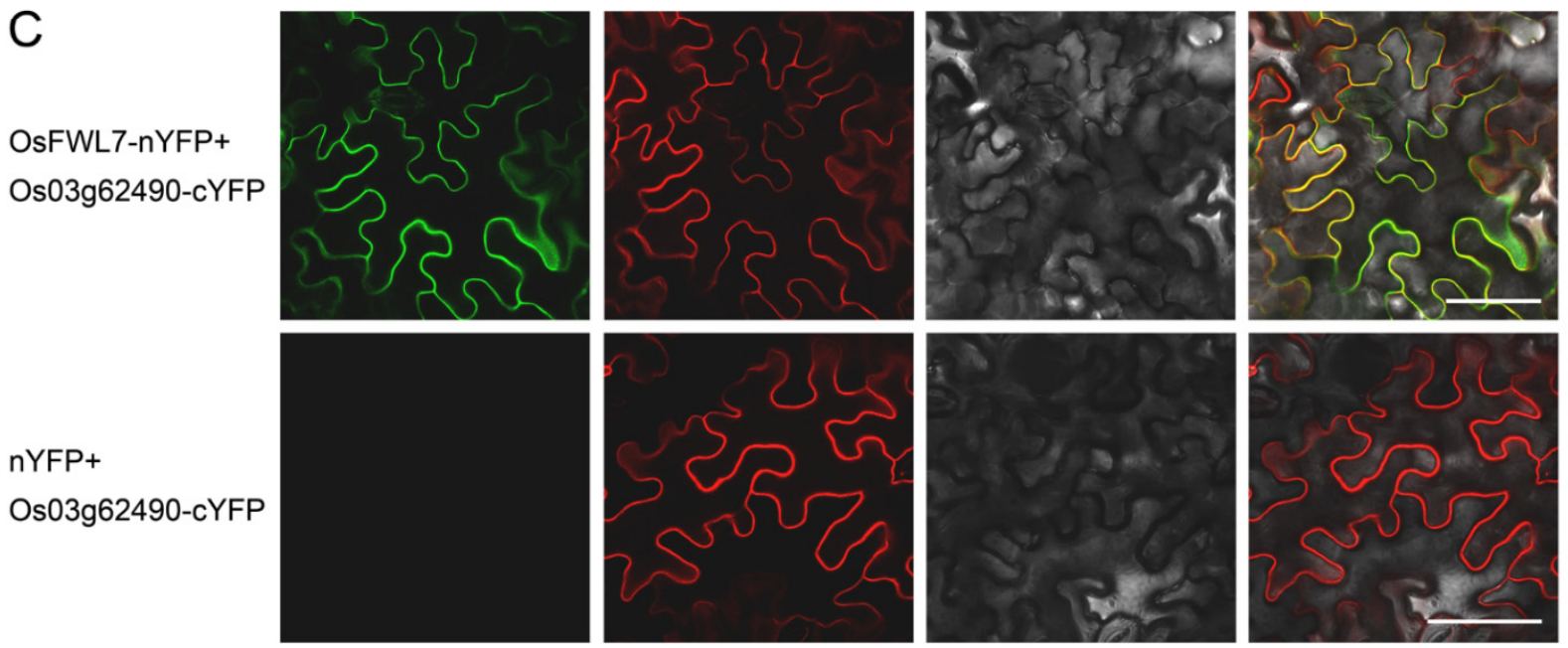

Figure 7. Detection of the interactions of rice FWL proteins with membrane microdomain marker proteins. (A) Yeast twohybrid assays of the interactions between rice FWL proteins and membrane microdomain marker proteins. Transformed yeast cells were cultured on SD-Leu-Trp control medium and SD-Leu-Trp-Ade-His selective medium. AD, activation domain; BD, DNA binding domain. (B,C) Bimolecular fluorescence complementation (BiFC) assays verify the interaction of OsFWL7 with LOC_Os04g38900 (B) and LOC_Os03g62490 (C). The OsSCAMP1 protein was fused with mCherry and used as the plasma membrane marker. The YFP fluorescence, mCherry fluorescence, bright field, and merged images are shown. Bar $=50 \mu \mathrm{m}$.

\section{Discussion}

$\mathrm{Cd}$ is a major heavy metal contaminant that is highly toxic to both plants and humans. Previous studies have suggested that plant $F W L$ genes play vital roles in the uptake and translocation of $C d[29,31,32,35,36,38]$. In the present study, both the uptake and rootto-shoot translocation of $\mathrm{Cd}$ were reduced in the osfwl7 mutants compared with the WT plants under $\mathrm{Cd}$ exposure (Figure 3). Similarly, $\mathrm{Cd}$ translocation was also decreased in the OsFWL4-knockdown plants [36]. When cultured in a liquid medium containing Cd, yeast cells expressing OsFWL7 accumulated markedly less Cd than the negative controls [36], suggesting that $O s F W L 7$ inhibits $\mathrm{Cd}$ accumulation in cells. Additionally, the expression level of OsNramp5, a major transporter involved in Cd uptake, was lower in osfwl7 mutants than in the WT under Cd treatment (Figure 5). Therefore, OsFWL7 affects Cd accumulation in rice.

Micronutrient metals, such as $\mathrm{Mn}, \mathrm{Cu}$, and $\mathrm{Fe}$, are essential for plant growth and development. Mn levels in both roots and shoots of osfwl7 mutants were markedly lower than in those of the WT under normal growth conditions (Figure 4A,E). Similarly, the shoot Mn level was significantly reduced in the OsFWL4-knockdown plants [36]. The transcript levels of OsNramp5, which is also a major transporter for Mn uptake, as well as of another Mn transporter, OsNramp6, were lower in the mutants than in the WT under normal conditions (Figure 5). Additionally, $\mathrm{Cu}$ levels in the roots and Fe levels in the shoots of osfwl7 mutants grown under normal conditions were markedly lower than those of the WT (Figure 4B,G). Therefore, OsFWL7 plays a role in micronutrient metal accumulation in rice.

In this study, the growth of both WT and osfwl7 mutant plants was severely inhibited following their exposure to $50 \mu \mathrm{M} \mathrm{Cd}$ for 10 days. However, the mutants grew slightly better than the WT (Figure 2), suggesting that the former were less sensitive to Cd stress. This result was consistent with the fact that osfwl7 mutants accumulated less $\mathrm{Cd}$; thus, suffered from less toxicity of this heavy metal (Figure 3). Interestingly, the root length of osfwl7 mutants grown under normal conditions was slightly lower than that of the WT, but the shoot dry weight of the mutants was significantly higher (Figure 2). Previous studies 
suggest that plant FWL proteins can act as the regulators of organ size $[19,22,26,34,38]$. Hence, OsFWL7 may also play a role in the regulation of organ development in rice.

Oligomerization of membrane proteins plays important roles in cell processes, such as membrane trafficking and signal transduction $[49,50]$. Previous studies suggest that the AtPCR2, OsFWL4, and OsPCR1/FWL5 proteins can form homo-oligomers in the plasma membrane to form the pores of the transporter $[30,36,38]$. In the present study, the seven membrane-bound rice FWL proteins were found to self-interact and interact with one another in the yeast cells (Figure 6A). The self-interaction of OsFWL7 was further confirmed by BiFC assays (Figure 6B). These results indicate that the rice FWL proteins form both homo- and hetero-oligomers in the cell membrane. Such homo- and hetero-oligomerization of proteins has also been observed in plant ammonium transporters [51,52].

Numerous studies have suggested that plasma membrane-associated plant FWL proteins perform diverse functions, such as cell division and organ development control, and heavy metal uptake and translocation [24,25]. However, the mechanisms underlying their distinct roles remain elusive. Recent studies have established that the GmFWL1 protein is located in plasma membrane microdomains $[27,28]$, shedding light on the molecular function of plant FWL proteins. Membrane microdomains are sub-compartments of biological membranes and comprise special lipids and proteins $[23,45]$. They play important roles in diverse biological processes, such as membrane transport and signal transduction [45,53]. Hence, plasma membrane microdomain-localized plant FWL proteins may be involved in transmembrane transportation of metal ions and signaling molecules, thus, affecting metal ion homeostasis and/or organ growth.

Membrane microdomains harbor specific proteins, such as remorins and prohibitins $[45,46]$. Our yeast two-hybrid assays revealed that six plasma membranebound rice FWL proteins interact with the prohibitin family protein LOC_Os03g62490, five interact with the prohibitin family protein LOC_Os04g38900, three interact with the remorin family protein LP1, and one interacts with the remorin family protein GSD1 (Figure 7A). The interactions between OsFWL7 and the two prohibitin family proteins were further verified by BiFC assays (Figure 7B,C). The results obtained indicate that rice FWL proteins interact with membrane microdomain marker proteins and may be located in membrane microdomains, similar to GmFWL1. In fact, OsPCR1/FWL5 was found to be specifically localized to the detergent-resistant membrane [38], which is thought to be similar to a membrane microdomain [53].

\section{Materials and Methods}

\subsection{Plant Materials and Treatments}

The osfwl7a and osfwl7b mutants were generated previously [37]. The WT rice O. sativa L. ssp. japonica variety Zhonghua 11 was used as the control.

Rice seeds were disinfected via treatment with $5 \% \mathrm{NaClO}$ for $20 \mathrm{~min}$ and washed with sterile water. The seeds were then incubated in sterile water for 2 days at $30{ }^{\circ} \mathrm{C}$ in the dark. The germinated seeds were grown in distilled water in a growth chamber under a light/dark cycle of $14 / 10 \mathrm{~h}$ and at a day/night temperature of $30{ }^{\circ} \mathrm{C} / 25^{\circ} \mathrm{C}$. On day 3, seedlings with uniform growth were cultured in Kimura B solution for another 3 days before treatment. For the expression analysis of rice FWL genes under Cd stress, WT seedlings were grown in Kimura B solution supplemented with different concentrations of $\mathrm{Cd}$ for $20 \mathrm{~h}$. $\mathrm{Cd}$ was added in the form of $\mathrm{CdCl}_{2}$. For the expression analysis of rice heavy metal transporter genes, the WT and mutant seedlings were grown in Kimura B solution with or without $50 \mu \mathrm{M}$ Cd for 3 days. For tissue-specific expression analysis of OsFWL7, different tissues were sampled from the well-grown field plants of Zhonghua 11. All sampled tissues were immediately frozen in liquid nitrogen and stored at $-80{ }^{\circ} \mathrm{C}$ until assayed.

To analyze Cd tolerance, the WT and mutant seedlings were grown in Kimura B solution containing $50 \mu \mathrm{M} \mathrm{Cd}$ for 10 days. Leaf pigments were measured according to the method described by Arnon [54]. 


\subsection{Subcellular Localization Analysis}

The coding region of OsFWL7 without the stop codon was amplified, cloned into the pAN580-GFP vector, and transformed into rice protoplasts. The OsSCAMP1-mCherry vector was co-transformed and used as the plasma membrane marker [55]. Fluorescence signals were observed using the LSM 700 confocal laser scanning microscope (Carl Zeiss, Jena, Germany). The PCR primers used for the construction of the subcellular localization vector are listed in Table S1.

\section{3. $R N A$ Isolation and $R T-q P C R$}

Total RNA was isolated using the RNAsimple Total RNA Isolation Kit (Tiangen, Beijing, China). Next, $1 \mu \mathrm{g}$ of total RNA was reverse-transcribed using the PrimeScript RT reagent Kit with gDNA Eraser (Takara, Dalian, China). RT-qPCR was performed using the CFX Connect Real-Time PCR system (Bio-Rad, Hercules, CA, USA). Each reaction mixture had a final volume of $25 \mu \mathrm{L}$, containing $2 \mu \mathrm{L}$ of cDNA template, $12.5 \mu \mathrm{L}$ of TB Green Premix Ex Taq II (Takara), and $0.4 \mu \mathrm{M}$ gene-specific primers. The PCR cycle was as follows: initial incubation at $95{ }^{\circ} \mathrm{C}$ for $30 \mathrm{~s}$, followed by 40 cycles at $95^{\circ} \mathrm{C}$ for $5 \mathrm{~s}$ and at $60{ }^{\circ} \mathrm{C}$ for $34 \mathrm{~s}$. We then performed melting curve analysis of amplicons to determine the specificity of PCR. Rice Actin1 or ubiquitin genes were used for data normalization. We used the $2^{-\Delta \Delta C T}$ method to calculate relative expression levels of target genes. Primers used for RT-qPCR are listed in Table S1.

\subsection{Yeast Two-Hybrid Assay}

The coding regions of the rice $F W L$ genes were cloned into the pGBKT7 bait vector and pGADT7 prey vector. The two remorin and two prohibitin genes were cloned into the pGADT7 vector. The bait and prey vectors were co-transformed into yeast strain AH109 using the Yeastmaker Yeast Transformation System 2 kit (Clontech, Dalian, China). After culturing on SD-Leu-Trp medium for 2 days, the interactions between the bait and prey were detected on selective SD-Leu-Trp-Ade-His medium. Yeast strains harboring the OsFWL-BD and empty pGADT7 vectors, the OsFWL-AD and empty pGBKT7 vectors, or the empty pGADT7 and pGBKT7 vectors were used as negative controls. All assays were repeated at least twice. The PCR primers used for the construction of yeast hybridization vectors are listed in Table S1.

\subsection{BiFC Assay}

The coding sequence of OsFWL7 was cloned into the p2YN and p2YC vectors to generate OsFWL7-YN and OsFWL7-YC constructs, respectively. The coding sequences of the two prohibitin genes were cloned into the $\mathrm{p} 2 \mathrm{YC}$ vector. The constructs were transformed into Agrobacterium tumefaciens strain EHA105 and transfected Nicotiana benthamiana leaves. The fluorescence was monitored using the LSM 700 confocal laser scanning microscope (Carl Zeiss). The PCR primers used for the construction of BiFC vectors are listed in Table S1.

\subsection{Measurement of Heavy Metal Levels}

Heavy metal levels in different tissues were determined according to the methods described by Zhang et al. [56]. In brief, the roots of hydroponically cultured seedlings were soaked in $20 \mathrm{mM}$ EDTA for $15 \mathrm{~min}$ and washed with deionized water. The root and shoot samples were dried at $80^{\circ} \mathrm{C}$ for 3 days and ground to a fine powder using an analytical mill (Cole-Parmer, Vernon Hills, IL, USA). Then, the samples ( $0.5 \mathrm{~g}$ ) were digested with $\mathrm{HNO}_{3}$ and $\mathrm{H}_{2} \mathrm{O}_{2}$ in a microwave digestion instrument (MARS 5; CEM, Matthews, NC, USA). Cd and micronutrient metal levels were measured using inductively coupled plasma optical emission spectrometry (ICP-OES, Thermo Scientific iCAP 6300; Thermo Fisher Scientific, Grand Island, NY, USA). 


\subsection{Statistical Analysis}

All data are presented as mean and standard deviation of replicates. The statistical significance of differences in means was evaluated using Student's $t$-test. Column charts were produced using SigmaPlot 10.0.

\section{Conclusions}

In summary, OsFWL7 encodes a plasma membrane protein that regulates $\mathrm{Cd}$ and micronutrient metal accumulation in rice. The rice FWL proteins interact with themselves and one another and may be located in membrane microdomains.

Supplementary Materials: The following are available online at https:/ / www.mdpi.com/article/10 $.3390 /$ ijms222212583/s1.

Author Contributions: H.Z. (Hao Zhang) and X.Z. designed the study; Q.G., L.L., H.Z. (Haiying Zhou), X.L., W.L., Y.M., Y.Y. and J.J. performed the experiments; Q.G. and L.L. analyzed the data; and Q.G., H.Z. (Hao Zhang) and X.Z. wrote the manuscript. All authors have read and agreed to the published version of the manuscript.

Funding: This research was funded by the Six Talent Peaks Project in Jiangsu Province (SWYY151), the Priority Academic Program Development of Jiangsu Higher Education Institutions, the Natural Science Foundation of Jiangsu Provincial Department of Education (19KJB180011), the Natural Science Research Program of Huai'an Municipality (HAB202155), and the Innovation and Entrepreneurship Training Program of College Students in Jiangsu Province (202110323012Z).

Data Availability Statement: All data are presented as figures and Supplementary Materials, which are included in this paper.

Acknowledgments: We thank the anonymous reviewers for their constructive comments and suggestions.

Conflicts of Interest: The authors declare no conflict of interest. The funders had no role in the design of the study; in the collection, analyses, or interpretation of data; in the writing of the manuscript, or in the decision to publish the results.

\section{References}

1. Hansch, R.; Mendel, R.R. Physiological functions of mineral micronutrients (Cu, Zn, Mn, Fe, Ni, Mo, B., Cl). Curr. Opin. Plant Biol. 2009, 12, 259-266. [CrossRef] [PubMed]

2. Clemens, S.; Ma, J.F. Toxic heavy metal and metalloid accumulation in crop plants and foods. Annu. Rev. Plant Biol. 2016, 67, 489-512. [CrossRef]

3. Ismael, M.A.; Elyamine, A.M.; Moussa, M.G.; Cai, M.; Zhao, X.; Hu, C. Cadmium in plants: Uptake, toxicity, and its interactions with selenium fertilizers. Metallomics 2019, 11, 255-277. [CrossRef]

4. Sasaki, A.; Yamaji, N.; Yokosho, K.; Ma, J.F. Nramp5 is a major transporter responsible for manganese and cadmium uptake in rice. Plant Cell 2012, 24, 2155-2167. [CrossRef]

5. Ishimaru, Y.; Takahashi, R.; Bashir, K.; Shimo, H.; Senoura, T.; Sugimoto, K.; Ono, K.; Yano, M.; Ishikawa, S.; Arao, T.; et al. Characterizing the role of rice NRAMP5 in manganese, iron and cadmium transport. Sci. Rep. 2012, 2, 286. [CrossRef] [PubMed]

6. Ishikawa, S.; Ishimaru, Y.; Igura, M.; Kuramata, M.; Abe, T.; Senoura, T.; Hase, Y.; Arao, T.; Nishizawa, N.K.; Nakanishi, H. Ion-beam irradiation, gene identification, and marker-assisted breeding in the development of low-cadmium rice. Proc. Natl. Acad. Sci. USA 2012, 109, 19166-19171. [CrossRef]

7. Ueno, D.; Yamaji, N.; Kono, I.; Huang, C.F.; Ando, T.; Yano, M.; Ma, J.F. Gene limiting cadmium accumulation in rice. Proc. Natl. Acad. Sci. USA 2010, 107, 16500-16505. [CrossRef] [PubMed]

8. Miyadate, H.; Adachi, S.; Hiraizumi, A.; Tezuka, K.; Nakazawa, N.; Kawamoto, T.; Katou, K.; Kodama, I.; Sakurai, K.; Takahashi, H.; et al. OsHMA3, a $\mathrm{P}_{1 \mathrm{~B}}$-type of ATPase affects root-to-shoot cadmium translocation in rice by mediating efflux into vacuoles. New Phytol. 2011, 189, 190-199. [CrossRef] [PubMed]

9. Yan, J.; Wang, P.; Yang, M.; Lian, X.; Tang, Z.; Huang, C.F.; Salt, D.E.; Zhao, F.J. A loss-of-function allele of OsHMA3 associated with high cadmium accumulation in shoots and grain of Japonica rice cultivars. Plant Cell Environ. 2016, 39, 1941-1954. [CrossRef] [PubMed]

10. Shao, J.F.; Fujii-Kashino, M.; Yamaji, N.; Fukuoka, S.; Shen, R.F.; Ma, J.F. Isolation and characterization of a rice line with high Cd accumulation for potential use in phytoremediation. Plant Soil 2017, 410, 357-368. [CrossRef]

11. Sasaki, A.; Yamaji, N.; Ma, J.F. Overexpression of OsHMA3 enhances Cd tolerance and expression of Zn transporter genes in rice. J. Exp. Bot. 2014, 65, 6013-6021. [CrossRef] 
12. Yamaji, N.; Xia, J.; Mitani-Ueno, N.; Yokosho, K.; Feng Ma, J. Preferential delivery of zinc to developing tissues in rice is mediated by P-type heavy metal ATPase OsHMA2. Plant Physiol. 2013, 162, 927-939. [CrossRef] [PubMed]

13. Satoh-Nagasawa, N.; Mori, M.; Nakazawa, N.; Kawamoto, T.; Nagato, Y.; Sakurai, K.; Takahashi, H.; Watanabe, A.; Akagi, H. Mutations in rice (Oryza sativa) heavy metal ATPase 2 (OsHMA2) restrict the translocation of zinc and cadmium. Plant Cell Physiol. 2012, 53, 213-224. [CrossRef] [PubMed]

14. Takahashi, R.; Ishimaru, Y.; Shimo, H.; Ogo, Y.; Senoura, T.; Nishizawa, N.K.; Nakanishi, H. The OsHMA2 transporter is involved in root-to-shoot translocation of $\mathrm{Zn}$ and Cd in rice. Plant Cell Environ. 2012, 35, 1948-1957. [CrossRef]

15. Ishimaru, Y.; Suzuki, M.; Tsukamoto, T.; Suzuki, K.; Nakazono, M.; Kobayashi, T.; Wada, Y.; Watanabe, S.; Matsuhashi, S.; Takahashi, M.; et al. Rice plants take up iron as an $\mathrm{Fe}^{3+}$-phytosiderophore and as $\mathrm{Fe}^{2+}$. Plant J. 2006, 45, 335-346. [CrossRef]

16. Yuan, M.; Li, X.; Xiao, J.; Wang, S. Molecular and functional analyses of COPT/Ctr-type copper transporter-like gene family in rice. BMC Plant Biol. 2011, 11, 69. [CrossRef] [PubMed]

17. Yuan, M.; Chu, Z.; Li, X.; Xu, C.; Wang, S. The bacterial pathogen Xanthomonas oryzae overcomes rice defenses by regulating host copper redistribution. Plant Cell 2010, 22, 3164-3176. [CrossRef] [PubMed]

18. Deng, F.; Yamaji, N.; Xia, J.; Ma, J.F. A member of the heavy metal P-type ATPase OsHMA5 is involved in xylem loading of copper in rice. Plant Physiol. 2013, 163, 1353-1362. [CrossRef]

19. Frary, A.; Nesbitt, T.C.; Grandillo, S.; Knaap, E.; Cong, B.; Liu, J.; Meller, J.; Elber, R.; Alpert, K.B.; Tanksley, S.D. fw2.2: A quantitative trait locus key to the evolution of tomato fruit size. Science 2000, 289, 85-88. [CrossRef]

20. Cong, B.; Liu, J.P.; Tanksley, S.D. Natural alleles at a tomato fruit size quantitative trait locus differ by heterochronic regulatory mutations. Proc. Natl. Acad. Sci. USA 2002, 99, 13606-13611. [CrossRef]

21. Cong, B.; Tanksley, S.D. FW2.2 and cell cycle control in developing tomato fruit: A possible example of gene co-option in the evolution of a novel organ. Plant Mol. Biol. 2006, 62, 867-880. [CrossRef]

22. Guo, M.; Rupe, M.A.; Dieter, J.A.; Zou, J.; Spielbauer, D.; Duncan, K.E.; Howard, R.J.; Hou, Z.; Simmons, C.R. Cell Number Regulator1 affects plant and organ size in maize: Implications for crop yield enhancement and heterosis. Plant Cell 2010, 22, 1057-1073. [CrossRef]

23. Thibivilliers, S.; Farmer, A.; Libault, M. Biological and cellular functions of the microdomain-associated FWL/CNR protein family in plants. Plants 2020, 9, 377. [CrossRef] [PubMed]

24. Beauchet, A.; Gevaudant, F.; Gonzalez, N.; Chevalier, C. In search of the still unknown function of FW2.2/CELL NUMBER REGULATOR, a major regulator of fruit size in tomato. J. Exp. Bot. 2021, 72, 5300-5311. [CrossRef] [PubMed]

25. Cabreira-Cagliari, C.; Dias, N.C.; Bohn, B.; Fagundes, D.; Margis-Pinheiro, M.; Bodanese-Zanettini, M.H.; Cagliari, A. Revising the PLAC8 gene family: From a central role in differentiation, proliferation, and apoptosis in mammals to a multifunctional role in plants. Genome 2018, 61, 857-865. [CrossRef]

26. Li, Z.; He, C. Physalis floridana Cell Number Regulator1 encodes a cell membrane-anchored modulator of cell cycle and negatively controls fruit size. J. Exp. Bot. 2015, 66, 257-270. [CrossRef] [PubMed]

27. Libault, M.; Zhang, X.C.; Govindarajulu, M.; Qiu, J.; Ong, Y.T.; Brechenmacher, L.; Berg, R.H.; Hurley-Sommer, A.; Taylor, C.G.; Stacey, G. A member of the highly conserved FWL (tomato FW2.2-like) gene family is essential for soybean nodule organogenesis. Plant J. 2010, 62, 852-864. [CrossRef]

28. Qiao, Z.; Brechenmacher, L.; Smith, B.; Strout, G.W.; Mangin, W.; Taylor, C.; Russell, S.D.; Stacey, G.; Libault, M. The GmFWL1 (FW2-2-like) nodulation gene encodes a plasma membrane microdomain-associated protein. Plant Cell Environ. 2017, 40, 1442-1455. [CrossRef]

29. Song, W.Y.; Martinoia, E.; Lee, J.; Kim, D.; Kim, D.Y.; Vogt, E.; Shim, D.; Choi, K.S.; Hwang, I.; Lee, Y. A novel family of cys-rich membrane proteins mediates cadmium resistance in Arabidopsis. Plant Physiol. 2004, 135, 1027-1039. [CrossRef]

30. Song, W.Y.; Choi, K.S.; Kim, D.Y.; Geisler, M.; Park, J.; Vincenzetti, V.; Schellenberg, M.; Kim, S.H.; Lim, Y.P.; Noh, E.W.; et al. Arabidopsis PCR2 is a zinc exporter involved in both zinc extrusion and long-distance zinc transport. Plant Cell 2010, 22, 2237-2252. [CrossRef]

31. Qiao, K.; Wang, F.; Liang, S.; Wang, H.; Hu, Z.; Chai, T. Improved Cd, Zn and Mn tolerance and reduced Cd accumulation in grains with wheat-based cell number regulator TaCNR2. Sci. Rep. 2019, 9, 870. [CrossRef]

32. Qiao, K.; Tian, Y.; Hu, Z.; Chai, T. Wheat cell number regulator CNR10 enhances the tolerance, translocation, and accumulation of heavy metals in plants. Environ. Sci. Technol. 2019, 53, 860-867. [CrossRef]

33. Xu, J.; Xiong, W.T.; Cao, B.B.; Yan, T.Z.; Luo, T.; Fan, T.T.; Luo, M.Z. Molecular characterization and functional analysis of "fruit-weight 2.2-like" gene family in rice. Planta 2013, 238, 643-655. [CrossRef]

34. Ruan, B.; Shang, L.; Zhang, B.; Hu, J.; Wang, Y.; Lin, H.; Zhang, A.; Liu, C.; Peng, Y.; Zhu, L.; et al. Natural variation in the promoter of TGW2 determines grain width and weight in rice. New Phytol. 2020, 227, 629-640. [CrossRef] [PubMed]

35. Wang, F.; Tan, H.; Han, J.; Zhang, Y.; He, X.; Ding, Y.; Chen, Z.; Zhu, C. A novel family of PLAC8 motif-containing/PCR genes mediates Cd tolerance and Cd accumulation in rice. Environ. Sci. Eur. 2019, 31, 82. [CrossRef]

36. Xiong, W.T.; Wang, P.; Yan, T.Z.; Cao, B.B.; Xu, J.; Liu, D.F.; Luo, M.Z. The rice "fruit-weight 2.2-like" gene family member OsFWL4 is involved in the translocation of cadmium from roots to shoots. Planta 2018, 247, 1247-1260. [CrossRef]

37. Gao, Q.; Li, G.; Sun, H.; Xu, M.; Wang, H.; Ji, J.; Wang, D.; Yuan, C.; Zhao, X. Targeted mutagenesis of the rice FW 2.2-like gene family using the CRISPR/Cas9 system reveals OsFWL4 as a regulator of tiller number and plant yield in rice. Int. J. Mol. Sci. 2020, 21, 809. [CrossRef] 
38. Song, W.Y.; Lee, H.S.; Jin, S.R.; Ko, D.; Martinoia, E.; Lee, Y.; An, G.; Ahn, S.N. Rice PCR1 influences grain weight and Zn accumulation in grains. Plant Cell Environ. 2015, 38, 2327-2339. [CrossRef] [PubMed]

39. Jiang, L.; Liu, X.; Xiong, G.; Liu, H.; Chen, F.; Wang, L.; Meng, X.; Liu, G.; Yu, H.; Yuan, Y.; et al. DWARF 53 acts as a repressor of strigolactone signalling in rice. Nature 2013, 504, 401-405. [CrossRef]

40. Ding, Y.; Gong, S.; Wang, Y.; Wang, F.; Bao, H.; Sun, J.; Cai, C.; Yi, K.; Chen, Z.; Zhu, C. MicroRNA166 modulates cadmium tolerance and accumulation in rice. Plant Physiol. 2018, 177, 1691-1703. [CrossRef] [PubMed]

41. Wang, J.; Zhou, L.; Shi, H.; Chern, M.; Yu, H.; Yi, H.; He, M.; Yin, J.; Zhu, X.; Li, Y.; et al. A single transcription factor promotes both yield and immunity in rice. Science 2018, 361, 1026-1028. [CrossRef]

42. Lam, S.K.; Siu, C.L.; Hillmer, S.; Jang, S.; An, G.; Robinson, D.G.; Jiang, L. Rice SCAMP1 defines clathrin-coated, trans-golgi-located tubular-vesicular structures as an early endosome in tobacco BY-2 cells. Plant Cell 2007, 19, 296-319. [CrossRef]

43. Peris-Peris, C.; Serra-Cardona, A.; Sanchez-Sanuy, F.; Campo, S.; Arino, J.; San Segundo, B. Two NRAMP6 isoforms function as iron and manganese transporters and contribute to disease resistance in rice. Mol. Plant Microbe Interact. 2017, 30, 385-398. [CrossRef]

44. Yamaji, N.; Sasaki, A.; Xia, J.X.; Yokosho, K.; Ma, J.F. A node-based switch for preferential distribution of manganese in rice. Nat. Commun. 2013, 4, 2442. [CrossRef] [PubMed]

45. Yu, M.; Cui, Y.; Zhang, X.; Li, R.; Lin, J. Organization and dynamics of functional plant membrane microdomains. Cell Mol. Life Sci. 2020, 77, 275-287. [CrossRef]

46. Browman, D.T.; Hoegg, M.B.; Robbins, S.M. The SPFH domain-containing proteins: More than lipid raft markers. Trends Cell Biol. 2007, 17, 394-402. [CrossRef]

47. Liu, E.; Liu, Y.; Wu, G.; Zeng, S.; Tran Thi, T.G.; Liang, L.; Liang, Y.; Dong, Z.; She, D.; Wang, H.; et al. Identification of a candidate gene for panicle length in rice (Oryza sativa L.) via association and linkage analysis. Front. Plant Sci. 2016, 7, 596. [CrossRef]

48. Gui, J.; Liu, C.; Shen, J.; Li, L. Grain setting defect1, encoding a remorin protein, affects the grain setting in rice through regulating plasmodesmatal conductance. Plant Physiol. 2014, 166, 1463-1478. [CrossRef]

49. Cecchetti, C.; Pyle, E.; Byrne, B. Transporter oligomerisation: Roles in structure and function. Biochem. Soc. Trans. 2019, 47, 433-440. [CrossRef] [PubMed]

50. Engel, A.; Gaub, H.E. Structure and mechanics of membrane proteins. Annu. Rev. Biochem. 2008, 77, 127-148. [CrossRef] [PubMed]

51. Ludewig, U.; Wilken, S.; Wu, B.; Jost, W.; Obrdlik, P.; El Bakkoury, M.; Marini, A.M.; Andre, B.; Hamacher, T.; Boles, E.; et al. Homo- and hetero-oligomerization of ammonium transporter-1 NH4 uniporters. J. Biol. Chem. 2003, 278, 45603-45610. [CrossRef] [PubMed]

52. Yuan, L.; Gu, R.; Xuan, Y.; Smith-Valle, E.; Loque, D.; Frommer, W.B.; von Wiren, N. Allosteric regulation of transport activity by heterotrimerization of Arabidopsis ammonium transporter complexes in vivo. Plant Cell 2013, 25, 974-984. [CrossRef]

53. Malinsky, J.; Opekarova, M.; Grossmann, G.; Tanner, W. Membrane microdomains, rafts, and detergent-resistant membranes in plants and fungi. Annu. Rev. Plant Biol. 2013, 64, 501-529. [CrossRef] [PubMed]

54. Arnon, D.I. Copper enzymes in isolated chloroplasts. Polyphenoloxidase in Beta vulgaris. Plant Physiol. 1949, 24, 1-15. [CrossRef]

55. Zhu, J.; Ren, Y.; Zhang, Y.; Yang, J.; Duan, E.; Wang, Y.; Liu, F.; Wu, M.; Pan, T.; Hu, T.; et al. Subunit E isoform 1 of vacuolar $\mathrm{H}^{+}$-ATPase OsVHA enables post-Golgi trafficking of rice seed storage proteins. Plant Physiol. 2021. [CrossRef] [PubMed]

56. Zhang, H.; Yu, C.; Hou, D.; Liu, H.; Tao, R.; Cai, H.; Gu, J.; Liu, L.; Zhang, Z.; Wang, Z.; et al. Changes in mineral elements and starch quality of grains during the improvement of japonica rice cultivars. J. Sci. Food Agric. 2018, 98, 122-133. [CrossRef] 